\title{
VIRTUDES E LIMITES \\ DE UMA ESCRAVIDÃO QUANTIFICADA: A ESCRAVIDÃo EM SANTOS DO SÉCULO XIX
}

READ, Ian. The Hierarchies of Slavery in Santos, Brazil. 1822-1888. Stanford: Stanford University Press, 2012. 275 p.

Ao longo do século XIX, Santos se transformou de modorrenta cidade litorânea paulista a maior porto da América Latina e sede de um dos mais combativos movimentos portuários do Brasil. Ainda na segunda metade do XIX, antes de se tornar a "Barcelona Brasileira", Santos foi palco de um dos mais organizados movimentos abolicionista e republicano brasileiros. Meca de escravos fugidos das fazendas cafeeiras desde pelo menos a década de 1860, se não antes, Santos era também uma cidade cercada de quilombos, sobretudo na área do Cubatão, ao pé da Serra do Mar. O mais notável deles foi o Quilombo do Pai Felipe, transferido pelos abolicionistas, na década de 1880, para dentro da cidade. Tais agrupamentos de escravos fugidos estavam, por sua vez, cercados de bairros de africanos livres, que haviam reformado a antiga estrada que ligava São Paulo à ci- dade santista e permanecido no seu entorno. Ali se localizava o famoso quilombo de Santos, o Jabaquara, organizado e administrado por abolicionistas santistas e paulistanos, que abrigou alguns milhares de fugidos. A própria fundação do quilombo santista foi fruto de uma tradição. Desde a década de 1870, os santistas militavam pela alforria de escravos que vagavam aos montes pelas ruas da cidade, carregando e descarregando café nos trapiches e se envolvendo na antiga tradição portuária de saques e furtos de mercadorias. Muitos destes escravos eram propriedade de fazendeiros de café, que os enviavam para servir casas comissárias e trapiches. Assim, Santos sempre esteve marcada por um intenso trânsito de escravos, libertos e fugidos, os quais se misturavam ao crescente número de trabalhadores do porto, nacionais e imigrantes. Além disso, a cidade foi 
cenário de movimentos sociais e políticos ricos e complexos que marcaram a história de São Paulo. Porém, em si mesma, a cidade possuía apenas um sistema escravista de pouca monta, caracterizado pelo serviço doméstico, prestação de serviços - escravos e escravas ganhadores - e produção de alimentos. Ainda mais, a escravidão em Santos pode ser descrita como uma escravidão de pequena posse, discutida por numerosos autores, que já bem a caracterizaram.

O livro de Ian Read apresenta uma ampla e minuciosa pesquisa, realizada a partir do cruzamento de diferentes fontes impressas e manuscritas, como documentos judiciais e cartoriais, entre outros. Seu estudo, alegadamente baseado em uma visão weberiana, se escora no cruzamento destas diferentes fontes. Decerto, o livro oferece uma miríade de dados a respeito da escravidão praticada na cidade, em suas diferentes ruas, arredores, seu autor discrimina ocupação, idade, sexo e estado civil dos escravizados. A bibliografia citada é também ampla e atualizada, embora nem sempre os autores discutidos ao longo do livro sejam os mais adequados para a discussão do tema em tela.

No entanto, Hierarchies of Slavery in Santos falha ao não problematizar seus dados nem frente àquilo que já conhecemos sobre a cidade, nem em relação aos próprios dados coligidos, resultando que a ri- queza de informações oferecidas permaneça à espera de uma interpretação mais consistente. Uma análise das conclusões do autor sugere que ele não problematizou devidamente seus achados, apresentando como conclusões definitivas dados retirados de fontes fragmentárias e, muitas vezes, contraditórias. Em consequência, o livro apresenta uma série de descobertas originais que só poderão ser validadas após minucioso escrutínio das fontes e da historiografia relevante. Além disso, o livro apresenta informações errôneas. Por exemplo, Read afirma que

quando a emancipação, em meados da década de 1880 , se tornava mais próxima, o governo imperial criou o Fundo de Emancipação para apressar o processo de abolição gradual (p. 3).

No entanto, como sabemos, o Fundo de Emancipação havia sido criado muito antes, em 1871, pela Lei do Ventre Livre, e implementado em algumas cidades apenas em meados da década de 1880. Ademais, há numerosas inconsistências na grafia e no uso de acentos em nomes próprios brasileiros e termos em português, revelando um certo descuido editorial, o que, infelizmente, vem se tornando cada vez mais comum em publicações norteamericanas sobre o mundo lusófono. Por exemplo, além de erros gráficos, neste livro o acento circunflexo aparece invertido em todas as ocorrências. 
O livro está dividido em duas partes: uma primeira a respeito do perfil socioeconômico dos senhores; e uma segunda relativa aos escravos, que objetiva mostrar como as características senhoriais podem ser correlacionadas com as características dos escravos em termos de preço, idade, ocupação, saúde, entre outras. Assim, em seu desenvolvimento, o livro discute muitos temas e assuntos: as características das ruas santistas, o perfil da população escrava da cidade relacionando-o com o status econômico de seus proprietários, o mercado de escravos da cidade, os tipos de família escrava, o crescimento do porto, as posturas municipais, a saúde dos escravos etc. Apesar da extensa pesquisa e elaborada apresentação dos dados em figuras e tabelas, Hierarchies of Slavery in Santos apresenta lacunas importantes. Para começar, não discute a demografia escrava, a exemplo da evolução da população cativa local década a década, o que deixa o leitor com pouca base para aferir, além do peso real dessa população, a verdadeira natureza dos dados apresentados. Afinal, qual o tamanho do universo populacional de que trata? Este é um bom exemplo da ambivalência deste livro, que oferece um monte de dados minuciosos ao mesmo tempo em que sonega informações básicas aos leitores.

Já no capítulo "Neighborhoods and Inequality" (Vizinhanças e Desi- gualdade), o autor apresenta um diagrama, baseado nos 1.380 registros de casamento, que representa os laços existentes entre as diferentes famílias livres ricas, remediadas e pobres da cidade. Embora muito elaborado, o diagrama pouco acrescenta ao que já sabemos sobre casamento, amasiamento e laços de parentesco no Brasil do XIX, onde os ricos casavam-se com ricos e os pobres pouco casavam, constituindo famílias informais (alguns autores chamam-nas "ilegítimas" ou "naturais") por falta de fundos para custear os trâmites legais de uma união legitimada pela Igreja. Aqui, o autor perde a oportunidade de discutir seus dados frente à bibliografia existente sobre a família paulista (especialmente Maria Odila Leite da Silva Dias, Eni Mesquita Samara e Maria Luíza Marcílio), que já mostrou a existência de laços e estruturas familiares muito mais heterogêneos e informais do que aqueles que caracterizavam a família patriarcal do engenho do Nordeste, descrita por Gilberto Freyre. Ao não elaborar seus dados, o autor não chega a iluminar a dinâmica social e política de Santos que conectava pobres e ricos por meio de laços de parentesco, de compadrio e que implicavam em submissão social.

Muitos outros quadros e figuras deste tipo são apresentados ao longo do livro sem a devida problematização. No item "Slave Punishemt" ("Punição de Escravos", p.114 em 
diante), por exemplo, o autor apresenta os diferentes códigos de posturas municipais de Santos como guias para conhecer a vida social da cidade e, sobretudo, a repressão e vigilância que pesavam sobre os escravos. Embora o autor lembre que "muitas destas posturas podem não ter sido expressamente obedecidas ", ele conclui que elas, "pelo menos, oferecem indícios de como os administradores imaginavam quão ordeira a cidade e quão responsáveis seus residentes deveriam ser". A partir dai sua discussão caminha de forma a tomar os diferentes artigos desses códigos como imagens da realidade, resultando numa cidade regrada e vigiada. Nada mais distante da realidade. Santos foi descrita por seus memorialistas e estudiosos como cidade altamente turbulenta - por exemplo, quarteleiros e valonguerios, isto é, moradores de dois bairros da cidade, guerreavam nas ruas -, além de suja, pouco policiada, cheia de escravos fugidos, imigrantes sem moradia, enfim, era esta uma cidade que todos, se podiam, evitavam devido à falta de condições higiênicas e ordenamento urbano.

Em muitas outras passagens o autor apresenta opiniões um tanto superficiais ou discussões pouco aprofundadas. Ao discutir alforria, ele declara que "os escravos tinham pouca oportunidade de forçar seus senhores a aceitar a alforria" (p. 158), opondo-se, sem cerimônia, a toda a bibli- ografia hoje existente sobre o tema, que vem mostrando a importância da iniciativa escrava na conquista da alforria. À página 160, ainda discutindo manumissão, mais uma conclusão desavisada. Afirma Read que, embora os pesquisadores tenham discriminado apenas três tipos de alforria (incondicional, onerosa e condicional), ele encontrou, em Santos, categorias mistas, isto é, alforrias condicionais e onerosas ao mesmo tempo. Também conclui que, em 16\% das cartas de alforria por ele estudadas, a liberdade não ficava garantida por aparecer apenas como uma promessa futura e que esta seria também uma originalidade de sua discussão. Estes dois temas, porém, não representam novidade alguma para os estudiosos do tema no Brasil, que vêm profusamente discutindo a complexidade do processo de alforria, inclusive em alguns livros que aparecem citados nas notas de Hierarchies of Slavery.

O capítulo "Ilness, Recovery, and Death" ("Doença, Convalescença e Morte") precisa ser melhor discutido, e urgentemente. Aqui, mais uma vez, o historiador apresenta dados tidos como inéditos, sem o devido esclarecimento de como eles foram obtidos, qual sua representatividade, sobre quais bases demográficas existem e como se poderia problematizar diagnósticos apresentados segundo padrões médicos rudimentares para os padrões atuais. Suas conclusões a 
respeito da ausência ou prevalência de epidemias na cidade são excessivamente peremptórias e definitivas para serem aceitas sem discussão.

Finalmente, o capítulo, "Manumissionists, Abolitionists, and Emancipation" ("Manumissionistas, Abolicionistas e Emancipação") se limita a apresentar os anos finais da década de 1880 , sem levar em conta a longa tradição abolicionista da cidade, tornando, as- sim, sua discussão superficial e impressionista. A ausência, não apenas neste capítulo, mas ao longo do livro, de uma abordagem crítica dos dados coligidos e de uma discussão do papel político desempenhado por Santos na conformação das lutas políticas de São Paulo na segunda metade do XIX, sobretudo do abolicionismo e republicanismo na cidade, se apresentam como os maiores problemas deste livro.

Maria Helena P. T. Machado hmachado@usp.br Universidade de São Paulo 
